\title{
Problems faced by patients and health service utilization experiences of gastrointestinal patients during lockdown due to COVID-19 pandemic
}

\author{
Hamid Ali Kalwar ${ }^{1}$, Lubna Kamani
}

\begin{abstract}
Objectives: The COVID-19 pandemic undermined the health service delivery and utilization of essential health care services globally. The current study therefore aimed to explore the health-seeking behaviors and challenges faced by patients for the management of gastrointestinal diseases.

Methods: A cross-sectional study was conducted at the outpatient department of Gastroenterology, Liaquat National Hospital, Karachi from March 2020 to July 2020 during the COVID-19 lockdown phase to explore patient experiences. Data was collected using a survey questionnaire. All patients of either gender were included after informed consent. Statistical analysis of the data was conducted using SPSS 21.0.

Results: A total of 184 patients were included who visited the hospital to seek medical services during the COVID-19 lockdown phase. The mean age of the population was 42.7 years $( \pm 16.13)$. Of these, $n=94$ (51.1\%) were males All patients had gastrointestinal issues with different comorbid conditions. One fortyseven $n=147(79.9 \%)$ presented with active complaints whereas, $n=37(20.1 \%)$ patients visited the hospital for their follow-up checkup. Out of 184 patients, $n=33$ (17.9\%) patients reported of having fear of visiting hospital due to COVID-19 outbreak. A statistically significant difference $p<0.001$ was noted between the history of comorbidities and patient delaying a visit to the healthcare due to the fear of COVID-19. Additionally, $61(73.5 \%)$ patients with co-morbidity faced difficulty in finding public transport $(\mathrm{p}=0.01)$. Nevertheless, $\mathrm{n}=171(93.0 \%)$ patients expressed satisfaction with the services provided by the hospital during the lockdown phase.

Conclusion: Patients with gastrointestinal conditions were largely affected by lockdown largely due to fear of contacting COVID-19 disease and inaccessibility to the public transportation. Widely available telemedicine service might overcome these shortcomings and ensure continuity of quality care.
\end{abstract}

KEYWORDS: Health service utilization, COVID-19 pandemic, Lockdown, Gastroenterology, Telemedicine.

doi: https://doi.org/10.12669/pjms.38.3.4799

How to cite this:

Kalwar HA, Kamani L. Problems faced by patients and health service utilization experiences of gastrointestinal patients during lockdown due to COVID-19 pandemic. Pak J Med Sci. 2022;38(3):517-522.

doi: https://doi.org/10.12669/pjms.38.3.4799

This is an Open Access article distributed under the terms of the Creative Commons Attribution License (http://creativecommons.org/licenses/by/3.0), which permits unrestricted use, distribution, and reproduction in any medium, provided the original work is properly cited.

Correspondence:

Dr. Lubna Kamani, MBBS, FCPS, MRCP (UK), FRCP (Lond), FACG. Associate Professor \& GI Residency Director,

Gastroenterology Department,

Liaquat National Hospital,

Karachi, Pakistan.

Email: lkamani@yahoo.com

* Received for Publication:

* $1^{\text {st }}$ Revision Received:

* $2^{\text {nd }}$ Revision Received:

* Final Revision Accepted:
June 2, 2021

June 14, 2021

October 4, 2021

October 20, 2021

\section{INTRODUCTION}

The COVID-19 pandemic caused widespread disruption in health, social, and economic spheres across the globe with drastic public health policy measures adding to the adversity. ${ }^{1}$ Although some weaknesses in pandemic risk management capacities of all countries were highlighted by global health monitoring bodies and the Global Preparedness Monitoring Board Report of 
2019 ${ }^{2-4}$ no significant efforts were taken by the governments to prepare for an infectious disease outbreak of this scale. Nevertheless, the novelty of the pathogen and its epidemiology has been a major factor resulting in uncertainties and delays ineffective management strategies. ${ }^{4}$ However, considerable heterogeneity in the degree of responsiveness and timing entailed varied public health outcomes across and within regions despite the implementation of overlapping response and management strategies. ${ }^{5}$

The current pandemic response not only dismantled healthcare systems but its impacts on population health are far-reaching ranging from hindrances in essential health services like routine immunization, treatment and management of other acute and chronic conditions, maternal and child health services, mental health services, and collapsing of healthcare systems. ${ }^{5-9}$ On the other hand, the negative impact on the socioeconomic domain of the societies resulted in unemployment, reduced individual productivity, business shutdowns, tourism suspension, disruption in routine education systems and supply chains, political issues, disruption of public transport systems, and shortages of human resources for health. ${ }^{10-12}$ While the health impacts of the pandemic are inevitable, a very high proportion of the population, particularly those who had existing chronic diseases faced immense hardships in seeking medical services amidst restrictive policies for pandemic management.,13 Modelling scientists indicated amplification of limitations and tradeoffs in routine healthcare services during the peak of the pandemic as the efforts of policy-makers and healthcare departments were in favour of outbreak management and containment. ${ }^{14,15}$

Significant reductions in attendance at healthcare facilities and utilization of reproductive health services, maternal and child healthcare, immunization coverage, and uptake of $\mathrm{HIV} /$ AIDS services were recorded during the Ebola Virus outbreak. ${ }^{16}$ These attitudes are further precipitated when there are shortages of personal protective equipment, perceptions of contracting the infectious disease at the routine healthcare facility, a high prevalence of COVID-19 related anxiety and fear, and a lack of trust in the service standards. ${ }^{17,18}$ Fear of contacting COVID-19 during routine healthcare visits to the hospitals has been documented as a major limiting factor to preventive as well as curative health service utilization in many countries. ${ }^{19}$
In Pakistan, the health service utilization for acute and chronic conditions also diminished due to fear of exposure with the potential disease carriers and accessibility issues as due to lockdowns and closure of routine transportation services, people faced difficulty in reaching the tertiary-care hospitals. ${ }^{20}$ The current study, therefore, aimed to explore the health-seeking behaviors of the patients visiting a tertiary healthcare facility for the management of acute and chronic conditions. The study also attempted to identify the challenges faced by patients in health services utilization during COVID-19 pandemic.

\section{METHODS}

A cross-sectional study was conducted at the Outpatient Department of Gastroenterology, Liaquat National Hospital, Karachi from March 2020 to July 2020 during the COVID-19 lockdown phase after approval of hospital ethics committee. A total number of 184 patients of either gender were included after informed consent.

Data Collection: Primary data were collected using a survey questionnaire including details about the issues faced by the patients in utilizing the hospital services during the pandemic-related lockdown. This included questions related to the reason for the hospital visit, active complaint and its duration, co-morbid conditions healthseeking details, availability of local physician, information related to delay in services, waiting in the emergency room (ER), type of emergency treatment received, denial for prescription, use of personal protective equipment/mask by the patients and the attendants, types of personal protective equipment used by the patients and the attendants, fear of visiting the facility due to COVID-19, modes of transportation and issues faced in reaching the hospital, and the patients' satisfaction with the hospital services.

Statistical Analysis: SPSS version $21.0^{21}$ was used for data analysis. Frequencies and percentages were computed for categorical. Mean and the standard deviation was analysed for continuous variables. Chi-square test was applied to study the effect of explanatory variables on the response variables where a p-value $\leq 0.05$ is considered as a significant difference.

Ethical Approval: (Ref: App \# 0516-2020-LNHERC, Dated: April 23, 2020). 
Table-I: Demographic and Clinical Characteristics of Patients suffering from Cirrhosis during COVID-19 Pandemic.

\begin{tabular}{|c|c|c|}
\hline Characteristics & Mean & $S D$ \\
\hline \multirow[t]{2}{*}{ Age } & 42.7 years & \pm 16.13 \\
\hline & $\begin{array}{c}\text { Frequency } \\
n=184\end{array}$ & $(\%)$ \\
\hline \multicolumn{3}{|l|}{ Age groups } \\
\hline $10-35$ & 70 & $(38 \%)$ \\
\hline $36-61$ & 82 & $(44.6 \%)$ \\
\hline $62-88$ & 32 & $(17.4 \%)$ \\
\hline \multicolumn{3}{|l|}{ Gender } \\
\hline Male & 94 & $(51.1 \%)$ \\
\hline Female & 90 & $(48.9 \%)$ \\
\hline \multicolumn{3}{|l|}{ Co-morbidities } \\
\hline Diabetes Mellitus & 01 & $(0.5 \%)$ \\
\hline Hypertension & 05 & $(2.7 \%)$ \\
\hline Ischemic heart disease & 01 & $(0.5 \%)$ \\
\hline $\begin{array}{l}\text { Other Issues (Including } \\
\text { arthritis, anxiety, depres- } \\
\text { sion, thyroid, allergies etc.) }\end{array}$ & 126 & $(68.5 \%)$ \\
\hline Liver diseases & 43 & $(23.4 \%)$ \\
\hline Asthma & 02 & $(1.1 \%)$ \\
\hline \multicolumn{3}{|l|}{ Active Complains } \\
\hline Abdominal pain & 79 & $(42.9 \%)$ \\
\hline Hepatic encephalopathy & 04 & $(2.2 \%)$ \\
\hline Fever & 02 & $(1.1 \%)$ \\
\hline Vomiting & 08 & $(4.3 \%)$ \\
\hline Diarrhea or Constipation & 03 & $(1.6 \%)$ \\
\hline Multiple Complains & 53 & $(28.8)$ \\
\hline Routine follow up & 33 & $(17.9 \%)$ \\
\hline No active complains & 02 & $(1.1 \%)$ \\
\hline \multicolumn{3}{|l|}{ Reason for hospital visit } \\
\hline Active complain & 147 & $(79.9 \%)$ \\
\hline Follow-up visit & 37 & $(20.1 \%)$ \\
\hline \multicolumn{3}{|l|}{ Length of complains } \\
\hline$<07$ days & 01 & $(0.5 \%)$ \\
\hline 08 - 28 days & 138 & $(75 \%)$ \\
\hline 29 - 48 days & 08 & $(4.3 \%)$ \\
\hline
\end{tabular}

\section{RESULTS}

A total of 184 patients were included who visited the hospital to seek medical services for their gastrointestinal issues during the COVID-19 lockdown phase. The mean age of the population was 42.7 years $( \pm 16.13)$ with patients falling within a range of 30 to 88 years. Out of 184 patients, $n=94$ (51.1\%) were males. All patients had gastrointestinal issues with different comorbid conditions (Table-I)

The most common complaint was abdominal pain in $\mathrm{n}=79(42.9 \%)$ followed by multiple gastrointestinal complaints, $n=53 \quad(28.8 \%)$. Another $\mathrm{n}=33(17.9 \%)$ visited the hospital for their routine follow visit. (Table-I).

One forty-seven $n=147$ (79.9\%) presented with active complaints with duration of complaint ranging from 8 days to 28 days. As shown in Table-II, $n=79(42.9 \%)$ of patients consulted a local general physician in their vicinity before coming to the hospital for their checkup, $n=82(44.6 \%)$ patients were attended by a local physician, $n=10$ $(5.4 \%)$ patients visited the local GP for their issue resolution while $\mathrm{n}=25(13.5 \%)$ patients visited ER for further management.

Out of 184 patients, $\mathrm{n}=170(92.4 \%)$ had an attendant with them during the treatment at the hospital. Also shown in Table-II, $\mathrm{n}=155$ (84.3\%) patients wore face masks inside the hospital. Out of 184 patients, $n=33(17.9 \%)$ patients reported of having fear of visiting hospital due to COVID-19 pandemic. In response to the accessibility to the hospital, $n=120(65.2 \%)$ patients reported of reaching the hospital using private mode of transportation during COVID-19 pandemic. Of these 64 patients, $n=83(45.1 \%)$ patients faced difficulty in finding public transport to reach the hospital. In regards to satisfaction with the services rendered by the hospital during the COVID-19 pandemic $\mathrm{n}=171 \quad(93.0 \%)$ patients expressed satisfaction with the services provided by the hospital during the lockdown phase.

The relation of demographic and clinical characteristics of patients with their experiences of health service utilization during the COVID-19 pandemic are described in Table-III. A statistically significant difference $p<0.001$ was noted between the history of comorbidities and patient avoidance of seeking healthcare due to fear of COVID-19. Patients without comorbid conditions (51.5\%) were more likely to avoid going to the healthcare facility due to fear of COVID-19 as opposed to patients with comorbidities (48.5\%). Similarly, difficulties in finding public transportation were faced by those who had comorbidities $(p=0.01)$.

\section{DISCUSSION}

The current study explored the challenges faced by patients during pandemic and lockdown phase in 
Table-II: Experiences of Patients related to Health Service Utilization during COVID-19 Pandemic.

\begin{tabular}{lc}
\hline Patient Experiences & Frequency (\%) n=184 \\
\hline Visit to local GP before going to the hospital & $79(42.9 \%)$ \\
Availability of local physician & $82(44.6 \%)$ \\
Visit to local GP for issue resolution & $10(5.40 \%)$ \\
Visited ER for the complain & $25(13.5 \%)$ \\
Faced waiting in the ER & $09(4.90 \%)$ \\
Emergency treatment provided & $20(10.9 \%)$ \\
Unable to get ER admission because of limited space. & $11(6.00 \%)$ \\
Number of attendants with the patients & \\
01 & $44(23.9 \%)$ \\
02 & $113(61.4 \%)$ \\
P3-04 & $27(14.6 \%)$ \\
Patients wearing masks of mask used by the patients & $155(84.3 \%)$ \\
Surgical mask/N95 & \\
Fabric mask & $62(33.7 \%)$ \\
Attendants wearing masks & $93(50.5 \%)$ \\
Avoided hospital due to fear of COVID-19 & $151(82.1 \%)$ \\
Mode of transportation & $33(17.9 \%)$ \\
Public & \\
Private & $64(34.8 \%)$ \\
Difficulty faced in finding public transport & $120(65.2 \%)$ \\
Satisfaction with the hospital service & $83(45.1 \%)$ \\
\hline
\end{tabular}

getting health service utilization within a developing country with limited resources. A large body of evidence highlighted the role of the COVID-19 pandemic in disrupting primary, secondary as well as tertiary healthcare services across the globe ${ }^{14}$ with substantial negative implications on the health systems. ranging from collapsing of the systems to ethical issues in making decisions related to

Table-III: Association of Demographic and Clinical Characteristics with Patient Experiences.

\begin{tabular}{|c|c|c|c|c|}
\hline & $\begin{array}{l}\text { Avoided hospital due } \\
\text { to the fear of COVID-19 }\end{array}$ & P value & $\begin{array}{l}\text { Difficulty faced in } \\
\text { finding transport }\end{array}$ & $P$ value \\
\hline \multicolumn{5}{|l|}{ Age } \\
\hline $10-35$ & $12(36.4 \%)$ & \multirow{3}{*}{0.575} & 34 (41.0\%) & \multirow{3}{*}{0.391} \\
\hline $36-61$ & $17(51.5 \%)$ & & $38(45.8 \%)$ & \\
\hline $62-88$ & $04(12.1 \%)$ & & $11(13.2 \%)$ & \\
\hline \multicolumn{5}{|l|}{ Gender } \\
\hline Male & $14(42.4 \%)$ & \multirow[t]{2}{*}{0.272} & $37(44.6 \%)$ & \multirow[t]{2}{*}{0.109} \\
\hline Female & $19(57.6 \%)$ & & $46(55.4 \%)$ & \\
\hline \multicolumn{5}{|l|}{ Comorbidities } \\
\hline No & $17(51.5 \%)$ & \multirow[t]{2}{*}{$<0.001$} & $22(26.5 \%)$ & \multirow{2}{*}{0.01} \\
\hline Yes & $16(48.5 \%)$ & & $61(73.5 \%)$ & \\
\hline \multicolumn{5}{|l|}{ Reason for visit } \\
\hline Active complain & $26(78.8 \%)$ & \multirow[t]{2}{*}{0.861} & $65(78.3 \%)$ & \multirow[t]{2}{*}{0.628} \\
\hline Routine follow-up & $07(21.2)$ & & $18(21.7 \%)$ & \\
\hline
\end{tabular}


priority treatment due to extensive burden on the healthcare systems. ${ }^{22}$ Anticipating the scale of health services interference due to the COVID-19 pandemic, the World Health Organization (WHO) devised and circulated operational guidelines for the uninterrupted functioning of essential healthcare services during an infectious disease outbreak in March 2020, following the declaration of COVID-19 as a pandemic. ${ }^{23}$ In line with the developing situations and emerging evidence from academia and research institutions, the technical document was subsequently revised in the second quarter of 2021. ${ }^{24}$

Pakistan being a lower-middle-income country (LMIC) also faced significant challenges in the management of the COVID-19 pandemic and its massive burden on the health system was equally experienced by the population. ${ }^{20}$ The current study revealed that patients with chronic conditions were largely affected by the pandemic-related policies as routine follow-up visits to the clinicians and the healthcare facility are inherent to the management regime of such patients, whereas the accessibility to the services was reduced due to pandemic-related policies as well as the fear of the infection. This is evident from the current findings where approximately half $(42 \%)$ of the patients visited a general healthcare practitioner in their area of residence instead of seeking care at the tertiary healthcare facility. These findings are incoherent with the results of a survey conducted in the United States where more than 50 percent of the patients admitted to postponing routine health care during the COVID-19 pandemic. ${ }^{25}$

In the present study, about one-third of patients with either active complaints or scheduled routine follow-up visits refrained from visiting the hospital due to fear of contracting COVID-19 infection. Fear of catching the infectious disease has been a major limiting factor in reducing health services utilization globally as well as in other endemics like Ebola virus and H1N1 outbreaks. ${ }^{26}$ In order to avoid delay in patient management and morbidity, it is recommended that telemedicine services should be widely accessible and integrated into the primary, secondary, and tertiary care during the pandemics to ensure effective continuity of care and other emergencies.

Interestingly, a significant proportion of the patients in the present study were accompanied by more than one attendant despite having institutional policies. In Pakistan most of the people lives in joint family system and also in a study by Roseland et al highlighted the role of families and support systems in the effective management of chronic diseases and improving patient care. ${ }^{27}$

Aside from the fear of disease, accessibility to health care services during health emergencies is another barrier underlying diminished health service utilization. Patients seeking health care often face hindrances due to the unavailability of public transportation augmented with restrictive social distancing policies. In our study, we noted that almost half of the patients $(50 \%)$ encountered challenges in terms of access to healthcare facilities due to the unavailability of public transport. This shortage and absolute unavailability of public transportation during the initial phase of the pandemic manifested as inadequacies in the effective follow-up of the patients with chronic illness, despite these challenges $93 \%$ of the patients in our study were satisfied with the services provided by the healthcare facility.

Limitations: As this study was conducted during the peak of the first COVID-19 wave in Pakistan which led to some challenges in recruiting patients for the study in addition to ensuring their safety. Due to these reasons, an exploratory research design was utilized. Moreover, findings from one healthcare facility may not be representative of the entire population therefore, cannot be generalized.

\section{CONCLUSION}

The current study highlighted some challenges encountered by the patients suffering from gastrointestinal diseases. The accessibility to the healthcare services was notably affected due to pandemic-related policies and lockdown. Fear of contracting the COVID-19 diseases, issues in finding public transportation were found to be the major limiting factor causing rifts in health service utilization by the study population. Widely available telemedicine service might overcome these shortcomings and ensure continuity of quality care.

Conflict of interest: None.

Funding: None.

\section{REFERENCES}

1. Zakoji M, Sundararaman T. Emerging good practices and lessons learnt to maintain essential health services during the COVID-19 pandemic. WHO South-East Asia J Public Heal. 2021;10(3):26. doi: 10.4103/2224-3151.309868 
2. World Health Organization. Global Preparedness Monitoring Board. A world at risk: annual report on global preparedness for health emergencies. Vol. Licence: C. Geneva; (19th September 2019). https://reliefweb. int/report/world/world-risk-annual-report-globalpreparedness-health-emergencies-global-preparedness. Accessed on Oct. 4, 2021

3. Nuclear Threat Initiative (NTI), Johns Hopkins Center for Health Security (JHU). Global Health Security Index: Building Collective Action and Accountability. 2019. https:// www.nti.org/about/projects/global-healthsecurity-index/ Accessed on Oct. 4, 2021

4. Dobbs M. National governance of public health responses in a pandemic? Eur J Risk Regul. 2020;11(2):240-248. doi: 10.1017/err.2020.39

5. Aven T, Bouder F. The COVID-19 pandemic: how can risk science help? J Risk Res. 2020;1-6. doi: 10.1080/13669877.2020.1756383

6. Ueda M, Martins R, Hendrie PC, McDonnell T, Crews JR, Wong TL, et al. Managing cancer care during the COVID-19 pandemic: Agility and collaboration toward a common goal. J Natl Compr Cancer Netw. 2020;18(4):366369. doi: $10.6004 /$ jnccn. 2020.7560

7. Turale S, Meechamnan C, Kunaviktikul W. Challenging times: ethics, nursing and the COVID-19 pandemic. Int Nurs Rev. 2020;67(2):164-167. doi: 10.1111/inr.12598

8. Chattu VK, Yaya S. Emerging infectious diseases and outbreaks: implications for women's reproductive health and rights in resource-poor settings. Springer. 2020;17:43. doi: 10.1186/s12978-020-0899-y

9. Sethi BA, Sethi A, Ali S, Aamir HS. Impact of Coronavirus disease (COVID-19) pandemic on health professionals. Pakistan J Med Sci. 2020;36(COVID19-S4):S6. doi: 10.12669/pjms.36.covid19-s4.2779

10. Sharifi A, Khavarian-Garmsir AR. The COVID-19 pandemic: Impacts on cities and major lessons for urban planning, design, and management. Sci Total Environ. 2020;142391. doi: doi: 10.1016/j.scitotenv.2020.142391

11. Tirachini A, Cats O. COVID-19 and public transportation: Current assessment, prospects, and research needs. J Public Transp. 2020;22(1):1. doi: 10.5038/2375-0901.22.1.1

12. Martin A, Markhvida M, Hallegatte S, Walsh B. Socioeconomic impacts of COVID-19 on household consumption and poverty. Econ disasters Clim Chang. 2020;4(3):453-479. doi: 10.1007/s41885-020-00070-3

13. Awucha NE, Janefrances OC, Meshach AC, Henrietta JC, Daniel AI, Chidiebere NE. Impact of the COVID-19 pandemic on consumers' access to essential medicines in Nigeria. Am J Trop Med Hyg. 2020;103(4):1630-1634. doi: 10.4269 /ajtmh.20-0838

14. Dignum F, Dignum V, Davidsson P, Ghorbani A, van der Hurk M, Jensen $M$, et al. Analysing the combined health, social and economic impacts of the corovanvirus pandemic using agent-based social simulation. Minds Mach. 2020;30(2):177-194. doi: 10.1007/s11023-020-09527-6

15. Rhodes T, Lancaster K, Lees S, Parker M. Modelling the pandemic: attuning models to their contexts. BMJ Glob Heal. 2020;5(6):e002914. doi: 10.1136/ bmjgh-2020-002914

16. Brolin Ribacke KJ, Saulnier DD, Eriksson A, von Schreeb J. Effects of the West Africa Ebola Virus Disease on HealthCare Utilization - A Systematic Review. Frontiers in Public Health. 2016;4:222. doi: 10.3389/fpubh.2016.00222

17. Lazzerini M, Barbi E, Apicella A, Marchetti F, Cardinale F, Trobia G. Delayed access or provision of care in Italy resulting from fear of COVID-19. Lancet Child Adolesc Heal. 2020;4(5):e10-e11. doi: 10.1016/S2352-4642(20)30108-5
18. Ahmed J, Malik F, Arif $\mathrm{T}$ Bin, Majid Z, Chaudhary MA, Ahmad J, et al. Availability of personal protective equipment (PPE) among US and Pakistani doctors in COVID-19 pandemic. Cureus. 2020;12(6). doi: 10.7759/ cureus. 8550

19. Shinan-Altman S, Levkovich I, Tavori G. Healthcare utilizationamongbreastcancerpatientsduringtheCOVID-19 outbreak. Palliat Support Care. 2020;18(4):385-391. doi: 10.1017/S1478951520000516

20. Noreen N, Dil S, Niazi S, Naveed I, Khan N, Khan F, et al. COVID 19 pandemic \& Pakistan; limitations and gaps. Glob Biosecurity. 2020;1(4). doi: 10.31646/gbio.63

21. IBM Corp. Released 2012. IBM SPSS Statistics for Windows. Armonk, NY: IBM Corp; 2012. https://www.ibm.com/ support/pages/how-cite-ibm-spss-statistics-or-earlierversions-spss Accessed on Oct. 4, 2021

22. Fernandez R, Lord $\mathrm{H}$, Halcomb E, Moxham L, Middleton R, Alananzeh I, et al. Implications for COVID-19: a systematic review of nurses' experiences of working in acute care hospital settings during a respiratory pandemic. Int J Nurs Stud. 2020;103637. doi: 10.1016/j.ijnurstu.2020.103637

23. World Health Organization. COVID-19: operational guidance for maintaining essential health services during an outbreak: Interim guidance. Geneva; (March 25 2020). https://apps.who.int/iris/handle/10665/331561 Accessed on Oct. 4, 2021

24. World Health Organization. Maintaining essential health services: operational guidance for the COVID-19 context: interim guidance. Geneva; (June 1 2020). https:// www.who.int/publications/i/item/WHO-2019-nCoVessential_health_services-2020.2 Accessed on Oct. 4, 2021

25. Patel S, Lorenzi N, Smith T, Carlson BR, Sternberg Jr P. Critical insights from patients during the COVID-19 pandemic. NEJM Catal Innov Care Deliv. 2020;1(4). doi: 10.1056/CAT.20.0299

26. Delamou A, Hammonds RM, Caluwaerts S, Utz B, Delvaux T. Ebola in Africa: Beyond epidemics, reproductive health in crisis. Lancet. 2014;384(2105):62363-62364. doi: 10.1016/S0140-6736(14)62364-3.

27. Rosland A-M, Piette JD. Emerging models for mobilizing family support for chronic disease management: A structured review. Chronic Illn. 2010;6(1):7-21. doi: $10.1177 / 1742395309352254$

\section{Author's Contribution:}

HAK: Data collection, data analysis. Writing first draft of manuscript.

LK: Conceptualization, protocol writing, and critical revision and final editing of manuscript.

Authors:

1. Hamid Ali Kalwar, MBBS, FCPS (Gasto). Consultant, Indus Hospital, Karachi, Pakistan.

2. Lubna Kamani, MBBS, FCPS, MRCP (UK), FRCP (Lond), FACG. Associate Professor \& GI Residency Director, Gastroenterology Department, Liaquat National Hospital, Karachi, Pakistan. 